\title{
Trece años de vigencia de la Ley 964 de 2005: análisis de sus efectos en el mercado de valores y puntos para tener en cuenta para futuras modificaciones*
}

\author{
Jorge Armando Corredor Higuera**
}

Fecha de recepción: 3 de abril de 2018

Fecha de evaluación: 16 de julio de 2018

Fecha de aceptación: 16 de julio de 2018

Resumen: Este artículo está encaminado a realizar un análisis de los efectos de la Ley 964 de 2005 desde su promulgación y determinar si dicha ley ha respondido a las dinámicas del mercado de valores en los últimos trece años, en especial, en lo concerniente a las crisis del mercado y a los sistemas de integración regional. Así, se analizarán los antecedentes de la Ley, los puntos cruciales de esta, para finalizar estableciendo cuáles son los retos del regulador y supervisor frente a las nuevas realidades del mercado de valores. La metodología de investigación de este trabajo consistió en el análisis de fuentes bibliográficas e información pública. Es de tipo descriptivo y de enfoque cualitativo, pues tiene el propósito de explicar las características del tema tratado con fundamento en el análisis de las fuentes de información.

Palabras clave: autorregulación; crisis; mercado de valores; regulación; supervisión.

Cómo citar: Corredor Higuera, J. A. (2019). Trece años de vigencia de la Ley 964 de 2005: análisis de sus efectos en el mercado de valores y puntos para tener en cuenta para futuras modificaciones. Revista Prolegómenos, 22(43), 21-41.

* Este documento se realizó entre la línea de investigación de Intervención del Estado y Autorregulación y forma parte de los productos de investigación desarrollados por el Observatorio de Derecho Financiero y del Mercado de Valores de la Universidad Externado de Colombia.

** Abogado de la Universidad Nacional de Colombia, especialista en Derecho Privado Económico de la misma Universidad, LL. M. Derecho Internacional, Inversiones, Comercio y Arbitraje, impartido por la Universidad de Heidelberg-Universidad de Chile. Docente investigador del Departamento de Derecho Financiero y Bursátil de la Universidad Externado de Colombia y profesor en pregrado y postgrado de la Facultad de Derecho de la misma Universidad. Correo electrónico: jorgearmando.corredor@gmail.com. Código Orcid https://orcid. org/0000-0003-4672-1789 


\title{
Thirteenth Anniversary of Law 964 of 2005: Analysis of its Effects on the Stock Market and Items to Consider for Future Modifications
}

\begin{abstract}
This paper aims at assessing the effects exerted by Law 964 of 2005 since its enactment and determining whether it has responded to the dynamics of the stock market in the last thirteen years, particularly with regard to the market crisis and regional integration systems. In addition, the paper discusses the background and critical items of the Law to identify the challenges facing regulators and supervisors against the new realities of the stock market. The research methodology of this descriptive and qualitative work consisted of examining literature sources and public information with the purpose of explaining the characteristics of the subject treated based on an analysis of information sources.
\end{abstract}

Keywords: Self-Regulation; Crisis; Stock Market; Regulation; Supervision.

\section{Décimo terceiro aniversário da lei 964 de 2005: Análise de seus efeitos no mercado de ações e itens a serem considerados para futuras modificações}

\footnotetext{
Resumo: Este artigo tem por objetivo avaliar os efeitos da Lei 964 de 2005, desde sua promulgação, e determinar se respondeu à dinâmica do mercado de ações nos últimos treze anos, particularmente no que diz respeito à crise de mercado e aos sistemas de integração regional. Além disso, o artigo discute os antecedentes e itens críticos da Lei para identificar os desafios que enfrentam reguladores e supervisores considerando as novas realidades do mercado de ações. A metodologia de pesquisa deste trabalho descritivo e qualitativo consistiu em examinar fontes bibliográficas e informações públicas com o objetivo de explicar as características do tema tratado a partir de uma análise de fontes de informação.
}

Palavras-chave: autorregulação; crise; mercado de ações; regulamento; supervisão 


\section{Introducción}

La Ley 964 de 2005 representó un cambio trascendental para el mercado de valores colombiano. Así, se establecieron criterios para crear un marco institucional moderno y eficiente en Colombia, que respondieran a las nuevas dinámicas internacionales de los mercados y a las recomendaciones internacionales, en especial a los postulados desarrollados por la Iosco sobre la materia (Ministerio de Hacienda y Crédito Público, 2004).

Bajo estos antecedentes, el 8 de julio de 2005 se promulgó la Ley 964 de 2005. Dicha ley marco determinó los objetivos y criterios de intervención del Estado en los mercados de valores, estableció un concepto de valor, implementó un proceso de autorregulación, creó mecanismos de protección a los inversionistas, configuró un régimen sancionatorio, desarrolló los criterios generales de los proveedores de infraestructura, autorizó la fusión de los dos supervisores existentes y consolidó la creación de un solo regulador en el mercado de valores colombiano.

Desde los trece años de su promulgación, la Ley 964 de 2005 se ha visto sometida a una serie de cambios regulatorios, nuevas dinámicas del mercado, integraciones regionales y crisis locales e internacionales, situaciones que llevan a reflexionar sobre cuál es el contexto actual de dicha ley y cuáles son los cambios que se deberían implementar con el fin de que el marco regulatorio y de supervisión respondan a las nuevas dinámicas locales e internacionales del mercado de valores. Bajo los anteriores precedentes, este trabajo busca analizar la siguiente pregunta de investigación: ¿cuáles deberían ser los cambios en materia de intervención en el mercado de valores colombiano con el fin de responder a las nuevas dinámicas locales e internacionales del mercado?

Con el fin de plantear una respuesta preliminar a esta pregunta de investigación, se parte del supuesto según el cual, si bien tanto la Ley 964 de 2005 como los decretos de intervención responden a estándares internacionales y a las dinámicas del mercado local, es necesario realizar desarrollos en procesos de intervención en temas tales como el concepto de valor, el modelo institucional, la red de seguridad financiera, los procesos de integración, el proceso de autorregulación y en el impacto de las nuevas tecnologías en los mercados de valores.

Como objetivo general, se busca identificar los cambios en materia de intervención del Estado en el mercado de valores colombiano en aras de responder a las nuevas dinámicas del mercado. Como objetivos específicos, se busca: (i) establecer el impacto de la Ley 964 de 2005 en el mercado de valores colombiano; (ii) identificar los puntos cruciales que deben ser revisados frente al proceso de intervención del Estado en el mercado bursátil; y (iii) proponer soluciones de tipo regulatorio y de supervisión frente a los cambios que requiere el mercado de valores frente a las dinámicas locales e internacionales de dicho mercado.

La metodología de investigación de este trabajo consistió en el análisis de fuentes bibliográficas e información pública. El trabajo es de tipo descriptivo y de enfoque cualitativo, pues tiene el propósito de explicar las características del tema tratado con fundamento en el análisis de las fuentes de información. Por la complejidad de la política pública a desarrollar, y por las limitaciones de este documento, se propondrá de forma general algunas posibles soluciones adicionales de intervención estatal. En el presente trabajo no se realizaron estudios de campo ni encuestas.

El documento desarrollará el impacto de la Ley 964 de 2005, para lo cual se analizarán los antecedentes del modelo institucional colombiano y el alcance de la citada ley. En segundo lugar, se describirán los procesos regulatorios de la ley, la situación del mercado en los últimos trece años, los mecanismos de integración y el impacto de la crisis local e internacional. Posteriormente, se establecerán los posibles puntos para reflexionar en temas tales como el concepto de valor, el modelo institucional, la red de seguridad financiera, los mecanismos de integración, el proceso de autorregulación y el impacto de las nuevas tecnologías en los mercados de valores. Finalmente, se plasmarán algunas conclusiones sobre el trabajo. 


\section{Impacto de la Ley 964 de 2005 en el mercado de valores colombiano}

\section{Antecedentes del modelo institucional del mercado de valores colombiano}

El mercado de valores en Colombia tiene como antecedentes la creación de la Bolsa Popular de Medellín en el año de 1901 y la Bolsa de Valores de Bogotá, la cual nació en 1928 del interés de algunos empresarios de la época de contar con un sistema de negociación de valores (Sarmiento, 2010, p. 87).

Por otra parte, la Misión Kemmerer representó un hito en la estructuración del mercado financiero colombiano, debido a la implementación del modelo de banca especializada, la creación de la Superintendencia Bancaria y la estructuración del Banco Central como emisor primario y director de la política monetaria (Sarmiento, 2010, p. 82).

Ahora bien, por razón de la creación de la Bolsa de Valores de Bogotá, se buscó instaurar una entidad que supervisara las actividades de las sociedades anónimas abiertas, motivo por el cual se creó la Superintendencia de Sociedades anónimas a través de la Ley 58 de $1931^{1}$.

La Ley 32 de 1979 actualizó los mecanismos de intervención del Estado en el mercado bursátil. Así, dicha ley creó la Comisión Nacional de Valores, cuya principal función era la de estimular, organizar, supervisar y regular el mercado de valores en nuestro país ${ }^{2}$. Igualmente, la citada Ley 32

1 No obstante, solo a partir del Decreto 1984 de 1939 empezó a funcionar la Superintendencia de Sociedades anónimas, la cual ejercía procesos de supervisión frente a las sociedades anónimas que no estuvieran bajo la vigilancia de la Superintendencia Bancaria (Superintedencia de Sociedades, 2012, p. 8).

2 Es de destacar que la citada Comisión contaba con las siguientes competencias: (i) regulación, (ii) organizar y llevar los registros de emisores e intermediarios de valores; (iii) autorizar la emisión de valores y los prospectos de información; (iv) solicitar información a los emisores e intermediarios de valores; (v) autorizar y supervisar a los proveedores de infraestructura; (vi) imponer sanciones de carácter administrativo (Congreso definió el concepto de oferta pública, el cual fue uno de los criterios rectores del mercado (López Roca, 2011, p. 161) y señaló que el mercado público de valores estará conformado por la emisión, suscripción, intermediación y negociación de los documentos emitidos en serie o en masa, respecto de los cuales se realice oferta pública.

Por otra parte, la Constitución Política de 1991 representó un punto fundamental para el modelo institucional del mercado de valores colombiano, al consagrar un esquema de intervención del Estado en los mercados a través de procesos de regulación y supervisión y al considerar al mercado bursátil como una actividad de interés público (Corte Constitucional, 2006). A su vez, con fundamento en el artículo 52 transitorio de la Constitución se creó la Superintendencia de Valores, entidad que tenía como competencia la supervisión de los mercados de valores en Colombia.

La Ley 35 de 1993 estableció el marco general de intervención del Estado en el mercado de valores. Así, de la citada Ley se pueden destacar: (i) los criterios de intervención del Estado en los citados mercados; (ii) la competencia de supervisión en cabeza de la Superintendencia de Valores; (iii) la facultad de sanción del Estado; (iv) la autorización de los procesos de titularización; (v) las funciones de intervención en el mercado de valores a través de la Sala General de la Superintendencia de Valores (Congreso de la República, 1993).

Con fundamento en el artículo 36 de la citada Ley 35 se promulgó el Decreto 653 de 1993, por medio del cual se expidió el Estatuto Orgánico del mercado público de valores. Es importante establecer que el citado Decreto estableció: (i) el alcance del mercado de valores en Colombia con fundamento en el concepto de oferta pública; (ii) los objetivos de intervención; (iii) la intervención en el mercado; (iv) las facultades de intervención de la Sala General: (v) la supervisión del mercado por parte de la Superintendencia de Valores; (vi) el régimen sancionatorio en cabeza de la Superintendencia de Valores; (vii) la regulación sobre uso de información privilegiada; (viii) el registro nacional de valores e intermediarios; ix) el

de la República, 1979). 
concepto de oferta pública; x) las reglas de emisión de bonos; xi) las reglas de emisión de acciones; xii) la regulación para comisionistas; y xiii) la regulación para proveedores de infraestructura (Ministerio de Hacienda y Crédito Público, 1993).

Bajo esta estructura institucional, se contaba con una Superintendencia de Valores, la cual cumplía funciones de supervisión en los mercados de valores y, a su vez, era regulador de dicho mercado a través de la Sala General de la Superintendencia de Valores. No obstante, la Corte Constitucional, a través de la Sentencia C-397 de 1995, estableció límites a las facultades de regulación de la Sala General de la Superintendencia de Valores y declaró la inexequibilidad de todo el Decreto 653 de 1995 (Corte Constitucional, 1995).

Finalmente, es de destacar la Resolución 400 de 1995, por medio de la cual se unifican y esquematizan todas las normas expedidas por la Sala General de la Superintendencia de Valores (Sala General de la Superintendencia de Valores, 1995) y la Resolución 1200 de 1995, por medio de las cuales se unificaron y actualizan todas las normas expedidas por la Superintendencia de Valores (Superintendencia de Valores, 1995). La esencia de dichas normas se encuentra hoy en día recogida en el Decreto 2555 de 2010.

\section{Alcance de la Ley 964 de 2005 y su impacto en el mercado de valores colombiano}

La Ley 964 de 2005 consagró una nueva visión para el mercado de valores colombiano, en aras de buscar que el modelo institucional esté acorde con los estándares internacionales establecidos por la arquitectura financiera internacional. Así, la citada Ley acogió varios de los criterios en materia de regulación y supervisión señalados por la Iosco (2010), en donde se pueden destacar: (i) los criterios de intervención del Estado en los mercados de valores: protección de inversionistas, mitigación de riesgo sistémico y, transparencia y disciplina en los mercados; (ii) normas sobre supervisión y cumplimiento; (iii) sistemas de suministro de información; (iv) cooperación entre supervisores; (v) emisores; (vi) intermediarios; (vii) infraestructura; (viii) fondos de inversión; (ix) mercados secundarios y; (x) procesos de autorregulación en los mercados de valores.

Dentro de los puntos más importantes a destacar de la Ley, se pueden mencionar:

\section{Concepto de valor}

Previo a la promulgación de la Ley 964 de 2005, en Colombia no existía una definición del concepto de valor. Así, la Ley 32 de 1979 definió el concepto de oferta pública y lo que comprende el mercado de valores en Colombia ${ }^{3}$. Igualmente, la Sala General de la Superintendencia de Valores era la única que podría determinar qué documentos tenían la condición y prerrogativas de los títulos valores ${ }^{4}(\mathrm{Su}$ perintedencia Financiera de Colombia, 2005).

Ahora bien, el artículo 2 de la Ley 964 de 2005 definió lo que se debe entender por valor en Colombia, estableció una lista taxativa de los valores, los diferenció de los títulos valores, facultó al Gobierno Nacional para establecer los nuevos valores

3 Ley 32 de 1979. Art. 6. “Conforman el mercado público de valores la emisión, suscripción, intermediación y negociación de los documentos emitidos en serie o en masa, respecto de los cuales se realice oferta pública, que otorguen a sus titulares derechos de crédito, de participación y de tradición o representativos de mercancías. Parágrafo. Se entiende por oferta pública aquella que se dirija a personas no determinadas o a sector o grupo de personas determinadas, o que se realice por algún medio de comunicación masiva para suscribir, enajenar o adquirir documentos de los mencionados en este artículo".

4 Ley 35 de 1993. Artículo 4. "Conforme a los objetivos de que trata el artículo 1o., el Gobierno intervendrá las actividades del mercado público de valores estableciendo normas de carácter general para los siguientes efectos: [...] g) Determinar, respecto de los tipos de documentos susceptibles de ser colocados por oferta pública, aquellos que tendrán el carácter y prerrogativas de los títulos valores, sean éstos de contenido crediticio, de participación o representativos de mercaderías, además de aquellos expresamente consagrados como tales en las normas legales; a tal propósito podrá establecer los casos en que los tenedores de títulos estarán agrupados en una organización colectiva que actuará a través de un representante". En igual sentido, véase artículo 1.2.7.1. de la Resolución 400 de 1995. 
y determinó unos criterios especiales de protección a dichos activos (Forigua, 2011, p. 412).

\section{Las actividades del mercado}

A partir de la Ley 964 de 2005, la intervención del Estado gira en torno al concepto de actividades del mercado de valores, el cual es mucho más flexible dentro del proceso de intervención por parte del Gobierno Nacional ${ }^{5}$. De esta manera, se materializa una regulación basada por cada tipo de actividad del mercado de valores en contraposición al criterio institucional para la regulación propio del artículo $1^{\circ}$ literal i) de la Ley 35 de 1994.

\section{Proceso de autorregulación del mercado de valores}

En concordancia con los estándares internacionales en la materia (Iosco, 2010), se institucionalizó un proceso de autorregulación intervenida en el mercado de valores colombiano (Rodríguez Fernández, 2014, p. 40). Así, se implementaron criterios normativos, de supervisión, disciplinarios y de certificación para los intermediarios de valores y las personas naturales vinculadas a dichos intermediarios (Ariza Marin, 2009).

\section{Prevalencia del sentido económico y financiero}

La Ley 964 de 2005 consagró un principio para el regulador, según el cual dentro de su actividad debe dar prelación al sentido económico y financiero sobre la forma cuando determine que: (i) un

5 Artículo 4o. Intervención en el mercado de valores. "Conforme a los objetivos y criterios previstos en el artículo 1 de la presente ley, el Gobierno Nacional intervendrá en las actividades del mercado de valores, así como en las demás actividades a que se refiere la presente ley, por medio de normas de carácter general para: a) Determinar las actividades que, en adición a las previstas en la presente ley, hacen parte del mercado de valores por constituir manejo, aprovechamiento e inversión de los recursos captados del público mediante valores, así como establecer su regulación. Igualmente, establecer la regulación aplicable a las actividades del mercado de valores señaladas en las normas vigentes”. derecho o instrumento es un valor; (ii) si alguna actividad es aquella de las cuales se requiere autorización; y (iii) cuando expida normas sobre protección a los inversionistas.

\section{Principio de finalidad de las operaciones}

El artículo 10 de la citada Ley determinó que a partir de la aceptación por el sistema de compensación y liquidación serán firmes, irrevocables, exigibles y oponibles frente a terceros las órdenes de transferencia de fondos o valores derivadas de operaciones sobre valores.

\section{Protección de las garantías otorgadas en la etapa de cumplimiento}

En aras de buscar un efectivo cumplimiento de las operaciones en el mercado de valores y evitar casos de incumplimiento que pueden llevar a la posterior pérdida de la confianza en el mercado, se estableció que las garantías entregadas por cuenta de un participante a un sistema de compensación y liquidación de operaciones, sean propias o de un tercero, que estén afectas al cumplimiento de operaciones u órdenes de transferencia aceptadas por el sistema, así como de la compensación y liquidación que resulten de estas, no podrán ser objeto de reivindicación, embargo, secuestro, retención u otra medida cautelar similar, administrativa o judicial, hasta tanto no se cumplan enteramente las obligaciones derivadas de tales operaciones u órdenes.

\section{Aplicación de la Ley al Banco de la República}

La Ley 964 de 2005 se aplica al Banco de la República en los siguientes puntos: (i) el Banco de la República estará sujeto a lo dispuesto en la Ley y a las regulaciones que de dicha ley se deriven en los que sea pertinente (Decreto 2555 de 2010); (ii) el Banco de la República estará bajo la supervisión de la Superintendencia Financiera como administrador del sistema de negociación (SEN) y del depósito centralizado de valores (DCV), y, cuando cumpla funciones de compensación y liquidación de valores y divisas; (iii) se aplicará al Banco lo pertinente al Registro Nacional de Profesionales del Mercado, teniendo en 
cuenta su naturaleza especial; (iv) el Banco de la República de forma excepcional podrá realizar nuevas actividades del mercado de valores siempre y cuando exista concepto previo del Gobierno Nacional; (v) las disposiciones sobre juntas directivas independientes no son aplicables al Banco de la República.

\section{Mecanismo de protección al inversionista}

La Ley 964 de 2005 creó un régimen de protección a los inversionistas en Colombia (Blanco, 2011) destacándose: (i) suministro de información a los inversionistas por parte de los emisores e intermediarios de valores; (ii) criterios en materia de gobierno corporativo; (iii) comités de auditoría; (iv) acuerdos entre accionistas; (v) reglamentos de suscripción de acciones.

\section{Sistema de información al mercado de valores}

Se creó el Sistema Integral de Información del Mercado de Valores (Simev) junto con sus tres registros, a saber: registro nacional de valores y emisores, registro nacional de agentes del mercado de valores y registro nacional de profesionales del mercado de valores. La finalidad de dichos sistemas es romper las posibles asimetrías de información entre los agentes del mercado y, de esta manera, poder contar con un mercado más transparente y competitivo.

\section{Eliminación de la Sala General y unificación de la regulación del mercado en cabeza del Gobierno Nacional}

Con el fin de evitar arbitrajes regulatorios se eliminó la Sala General de la Superintendencia de Valores y se unificó la regulación en el esquema de ley marco y decretos de intervención expedidos por el Gobierno Nacional.

\section{Autorizó la fusión de la Superintendencia Bancaria y la Superintendencia de valores}

Para evitar posibles arbitrajes en materia de supervisión se autorizó la fusión de las dos superintendencias (Consejo Nacional de Política Económica y
Social, 2005). Así, con la creación de la Superintendencia Financiera de Colombia se generó un modelo de supervisión integrado y unificado en donde una sola agencia conoce de temas prudenciales para los tres mercados (bancario, valores y seguros) y conductas del mercado (Estrada \& Gutiérrez, 2008), con el fin de facilitar la supervisión consolidada en materia de conglomerados financieros (Llewellyn, 2006, p. 15)

Finalmente, la Ley 964 de 2005 estableció criterios regulatorios en materia sancionatoria, sistemas de compensación y liquidación, cámaras centrales de riesgos de contraparte, depósito de valores, anotación en cuenta y sistemas de negociación y registro de operaciones.

\section{Principales aspectos} regulatorios y de mercado
materializados desde la
vigencia de la Ley 964 de 2005

\section{Evolución regulatoria a partir de la Ley 964 de 2005}

A través del Decreto 4327 de 2005 se fusionaron las dos superintendencias y se creó la Superintendencia Financiera de Colombia, como supervisor integrado para los tres mercados y unificado para temas de estabilidad financiera y conductas del mercado.

No obstante, el problema de la estructura creada a partir del Decreto 4327 de 2005 es que se le dio un fuerte énfasis bancario al proceso de supervisión institucional y basado en riesgo, motivo por el cual la supervisión no respondía del todo a las necesidades y dinámicas del mercado de valores colombiano.

En nuestra opinión, la crisis del mercado de valores llevó a que se modificara la estructura interna del supervisor en aras de fortalecer el proceso de supervisión del citado mercado. Así, a través del Decreto 1848 de 2016 se modificó la estructura interna de la Superintendencia Financiera de Colombia y se fortaleció el proceso de supervisión del mercado de valores mediante la creación de la 
delegatura adjunta para supervisión de emisores, administradores de activos e intermediarios de valores (Ministerio de Hacienda, Departamento Administrativo de la Función Pública, 2016).

Por otra parte, es importante establecer que el proceso regulatorio de los últimos trece años ha respondido tanto a las necesidades del mercado local como al trasplante jurídico de los estándares internacionales en materia de mercado de valores, representados en normas de soft law emitidas por las organizaciones gremiales internacionales (como es el caso de la Iosco, el Comité de Basilea, Banco de Pagos Internacional, el Consejo de Estabilidad financiera) y de algunas instituciones multilaterales como la OECD.

Así, en la tabla 1 se expondrán los principales referentes regulatorios del mercado de valores desde la promulgación de la Ley 964 de 2005 y se señalará cómo la mayoría de estos responden a un estándar internacional.

Tabla 1. Desarrollo de la Ley 964 de 2005.

\begin{tabular}{|c|c|c|}
\hline Norma & Ámbito & Estándar internacional o hecho que lo genera \\
\hline Decreto 3139 de 2006 & $\begin{array}{l}\text { Estructuración del Simev y sus correspondientes } \\
\text { registros }\end{array}$ & $\begin{array}{l}\text { Objetives and Principles of Securities Regulation } \\
\text { (Iosco) }\end{array}$ \\
\hline Decreto 1565 de 2006 & Autorregulación & $\begin{array}{l}\text { Objetives and Principles of Securities Regulation } \\
\text { (Iosco) }\end{array}$ \\
\hline Decreto 1941 de 2006 & Oferta pública de adquisición & Necesidad del mercado \\
\hline \multirow{3}{*}{ Decreto 2938 de 2007} & & $\begin{array}{l}\text { Objetives and Principles of Securities Regulation } \\
\text { (Iosco) }\end{array}$ \\
\hline & & Takeover regulation in the jurisdictions of some Iosco \\
\hline & & EMC members (Iosco) \\
\hline Decreto 2893 de 2007 & Cámaras de Riesgo Central de Contraparte & $\begin{array}{l}\text { Principles for financial market infrastructures (Bis- } \\
\text { Iosco) }\end{array}$ \\
\hline Decreto 1456 de 2007 & Sistema de Compensación y Liquidación & $\begin{array}{l}\text { Principles for financial market infrastructures (BIS- } \\
\text { Iosco) }\end{array}$ \\
\hline Decreto 3780 de 2007 & $\begin{array}{l}\text { Oferta pública de valores mediante la } \\
\text { construcción de libros de oferta }\end{array}$ & $\begin{array}{l}\text { Objetives and Principles of securities regulation } \\
\text { (Iosco) }\end{array}$ \\
\hline Decreto 1340 de 2008 & $\begin{array}{l}\text { Se reconoce la calidad de valores, se reglamentan } \\
\text { puntos del Simev y se reglamentan valores } \\
\text { objeto de negociación en las bolsas de productos } \\
\text { agropecuarios, industriales y otros commodities }\end{array}$ & Necesidad del mercado \\
\hline Decreto 1121 de 2008 & Intermediación de valores & $\begin{array}{l}\text { Objetives and Principles of Securities Regulation } \\
\text { (Iosco) }\end{array}$ \\
\hline Ley 1328 de 2009 & Estándares de protección al consumidor financiero & $\begin{array}{l}\text { High Level principles on financial consumer } \\
\text { protection (OECD) }\end{array}$ \\
\hline Decreto 2555 de 2010 & $\begin{array}{l}\text { Recopilación de toda la normatividad del mercado } \\
\text { de valores }\end{array}$ & $\begin{array}{l}\text { Política pública de esquematización de los decretos } \\
\text { de intervención }\end{array}$ \\
\hline Decreto 230 de 2010 & Titularización de activos no hipotecarios & Necesidades del mercado \\
\hline Decreto 2279 de 2010 & Formadores de liquidez en el mercado de valores & Necesidad del mercado para darle liquidez \\
\hline Decreto 1340 de 2012 & $\begin{array}{l}\text { Operaciones por cuenta propia de sociedades } \\
\text { comisionistas de bolsa }\end{array}$ & Necesidad del mercado \\
\hline Decreto 1242 de 2013 & Fondos de inversión colectiva & Iosco cuenta con 20 recomendaciones sobre el tema* \\
\hline Decreto 1243 de 2013 & Actividades de custodio de valores & $\begin{array}{l}\text { Standards for the Custody of Collective Investment } \\
\text { Schemes' Assets (Iosco) }\end{array}$ \\
\hline Decreto 1850 de 2013 & $\begin{array}{l}\text { Promoción y colocación de emisiones primarias en } \\
\text { los sistemas de valores del extranjero mediante } \\
\text { acuerdos o convenios de integración de bolsas de } \\
\text { valores. }\end{array}$ & Producto de los adelantos del MILA \\
\hline Decreto 2878 de 2013 & Operaciones de repo, simultáneas y TTV & Producto de la crisis de Interbolsa \\
\hline Decreto 2925 de 2013 & Proveedores de precios para valoración & $\begin{array}{l}\text { Principles for financial market infrastructures (Bis- } \\
\text { Iosco) }\end{array}$ \\
\hline Decreto 1019 de 2014 & Segundos mercados & $\begin{array}{l}\text { Estandares del Committee on Regulation of } \\
\text { Secondary Markets (Iosco) }\end{array}$ \\
\hline
\end{tabular}




\begin{tabular}{|c|c|c|}
\hline Norma & Ámbito & Estándar internacional o hecho que lo genera \\
\hline Decreto 032 de 2015 & Cámaras de Riesgo Central de Contraparte & $\begin{array}{l}\text { Principles for financial market infrastructures (Bis- } \\
\text { Iosco) }\end{array}$ \\
\hline Decreto 1403 de 2015 & Modificación régimen de fondos de capital privado & Iosco cuenta con 20 recomendaciones sobre el tema \\
\hline Decreto 1265 de 2015 & $\begin{array}{l}\text { Operaciones que se compensan y liquiden a través } \\
\text { de CCRC }\end{array}$ & $\begin{array}{l}\text { Principles for financial market infrastructures (Bis- } \\
\text { Iosco) }\end{array}$ \\
\hline Decreto 1247 de 2016 & Administración de portafolios de terceros & Necesidad del mercado \\
\hline Decreto 766 de 2016 & Garantías y limites en repos, simultáneas y TTV & Necesidad del mercado. \\
\hline Decreto 2219 de 2017 & $\begin{array}{l}\text { Operaciones que se compensan y liquiden a través } \\
\text { de una CRCC }\end{array}$ & $\begin{array}{l}\text { Principles for financial market infrastructures (Bis- } \\
\text { Iosco) }\end{array}$ \\
\hline Decreto 2090 de 2017 & $\begin{array}{l}\text { Fondos de inversión colectiva inmobiliaria y } \\
\text { titularización inmobiliaria }\end{array}$ & Iosco cuenta con 20 recomendaciones sobre el tema \\
\hline Decreto 1178 de 2017 & $\begin{array}{l}\text { Reglas de transparencia y homogenización de la } \\
\text { oferta pública de valores }\end{array}$ & $\begin{array}{l}\text { Objetives and Principles of securities regulation } \\
\text { (Iosco) }\end{array}$ \\
\hline Decreto 415 de 2018 & $\begin{array}{l}\text { Patrimonios adecuados de AFPS, comisionistas de } \\
\text { bolsas y SAI }\end{array}$ & $\begin{array}{l}\text { Criterios de la Iosco y el comité de Basilea sobre } \\
\text { patrimonios adecuados }\end{array}$ \\
\hline
\end{tabular}

*En materia de supervisión de la Superintendencia Financiera de Colombia, las instituciones financieras reciben el nombre de "vigiladas" en los términos del EOSF decreto 663 de 1993. Dichas recomendaciones pueden consultarse en la página de International Organization os Security Commissions: https://www.iosco.org/ search/index.cfm?criteria=investment $\% 20$ fund\&show=publicdocs

Fuente: creación propia.

\section{Memorando de entendimiento celebrado entre la \\ Superintendencia Financiera de Colombia y la AMv}

El artículo 25 de la Ley 964 de 2005 autorizó al supervisor financiero para celebrar memorandos de entendimiento con organismos de autorregulación, con el fin de fortalecer los procesos de supervisión y disciplina en el mercado de valores y evitar duplicidad de funciones. Con fundamento en lo anterior, el 9 de noviembre de 2007 se firmó el memorando de entendimiento celebrado entre la Superintendencia Financiera de Colombia y la AMv.

Dentro de los puntos críticos del citado memorando se destaca el artículo 5.1, por medio del cual se le otorgó a la AMv ser el supervisor de primera línea en las actividades de intermediación de valores, en especial en lo referente al tema de conductas y abusos en el mercado ( $\mathrm{Su}$ perintendencia Financiera de Colombia, Amv, 2007). Tal situación llevó en la práctica a una serie de interrogantes, en especial en cuanto al papel que cumplía la Superintendencia Financiera de Colombia frente a la AMv como supervisor de primera línea, llegando algunos a hablar de una delegación de funciones (Rodríguez Fernández, 2014, p. 88).

\section{Regulador unificado en el mercado de valores}

La Ley 964 de 2005 derogó la Sala General de la Superintendencia de Valores y unificó toda la actividad regulatoria del mercado de valores en cabeza del Gobierno Nacional. La finalidad de dicha medida fue la de evitar arbitrajes regulatorios que generaran cargas regulatorias ineficientes a las instituciones financieras y poder consolidar una regulación que respondiera a la dinámica propia de los conglomerados financieros.

No obstante este esquema institucional, compartimos la posición esgrimida por Baquero, según la cual dicha situación generó un conflicto de intereses al interior del regulador financiero, ya que el Ministerio de Hacienda, además de ser el regulador del mercado de valores, tiene la competencia a través de la Dirección General de Crédito Público y del Tesoro Nacional de emitir deuda pública, lo cual podría traer como consecuencia que la regulación del mercado de valores incentive el desarrollo y la compra de la deuda pública ${ }^{6}$ (Baquero, 2011).

6 Los TES (títulos de tesorería tipo B) son los valores más transados en el mercado de valores local, llegando su negociación a porcentajes del 70 al $80 \%$ del total de los valores transados en la Bolsa de Valores de Colombia (BvC). 


\section{Generalidad del mercado de valores colombiano}

En el mercado de valores colombiano los TES son los valores más transados, seguidos del mercado de renta variable y la deuda privada. No obstante, existe una altísima concentración del mercado bursátil en la negociación de TEs, tal y como

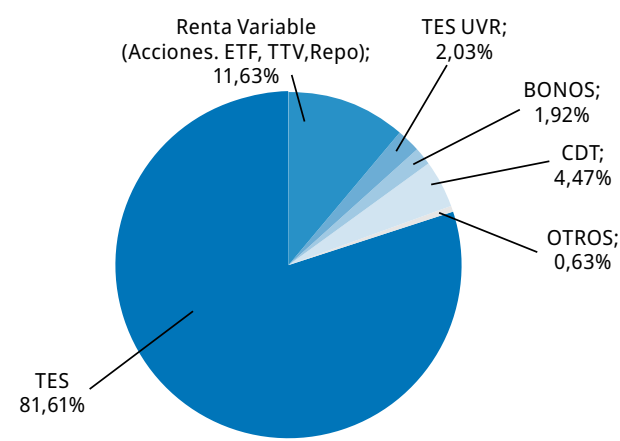

Fuente: tomado de la BVc, años 2016-2014.

Figura 2. Participación por instrumento en el total transado (2014)

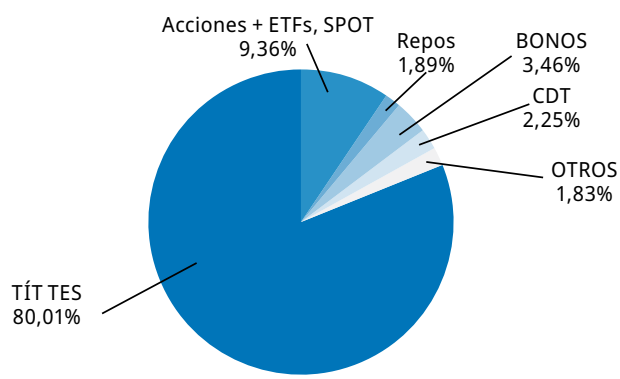

Fuente: tomado de la Bvc años 2016-2014. se expone a continuación a partir de datos aleatorios de varios años comprendidos del 2005 al 2017.

En cuanto al mercado accionario, se presenta el comportamiento del Colcap del año 2008 al 2018 y del IGBC del 2006 al 2013, de acuerdo con la información suministrada por la BVC y el Banco de la República:

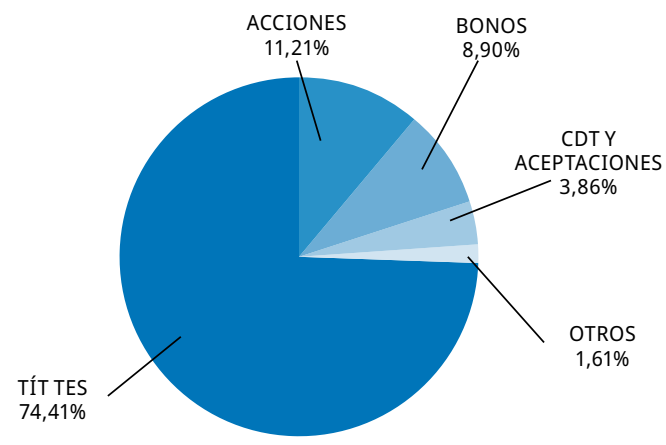

Fuente: tomado de la BVc, años 2012-2013.

Figura 4. Participación por instrumento en el total transado (2013)

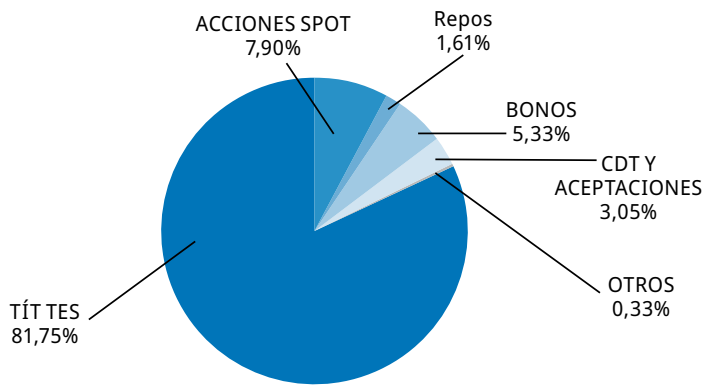

Fuente: tomado de la BVc, años 2012-2013.

Figura 5. Comportamiento del Colcap, 2008 a enero de 2018

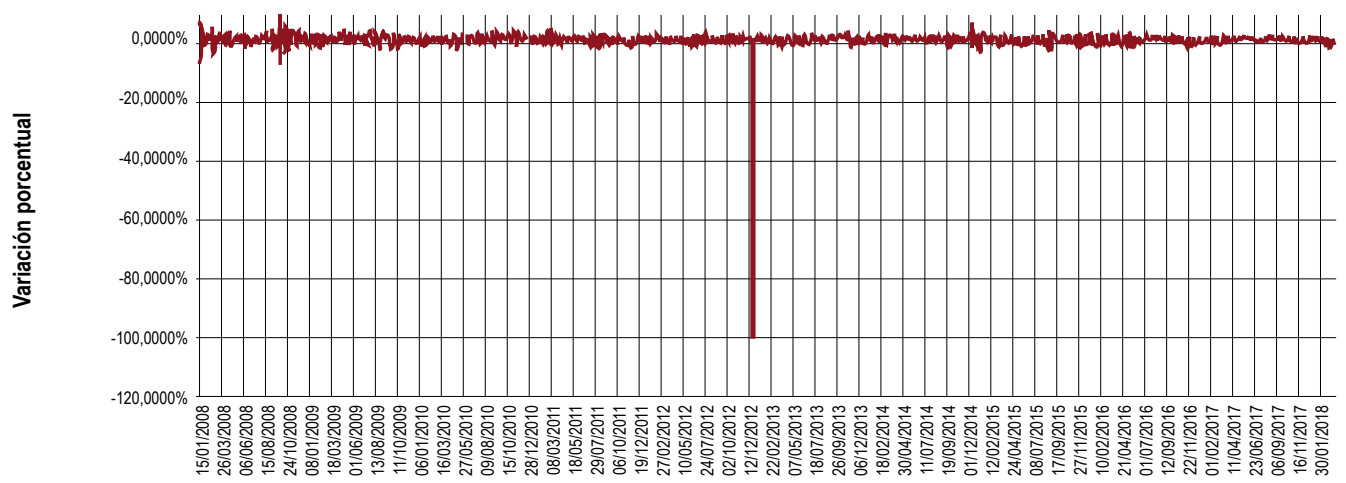

Fuente: tomado de la Bvc y Banco de la República. 
Figura 6. Comportamiento del IGBC, 2006 a octubre de 2013

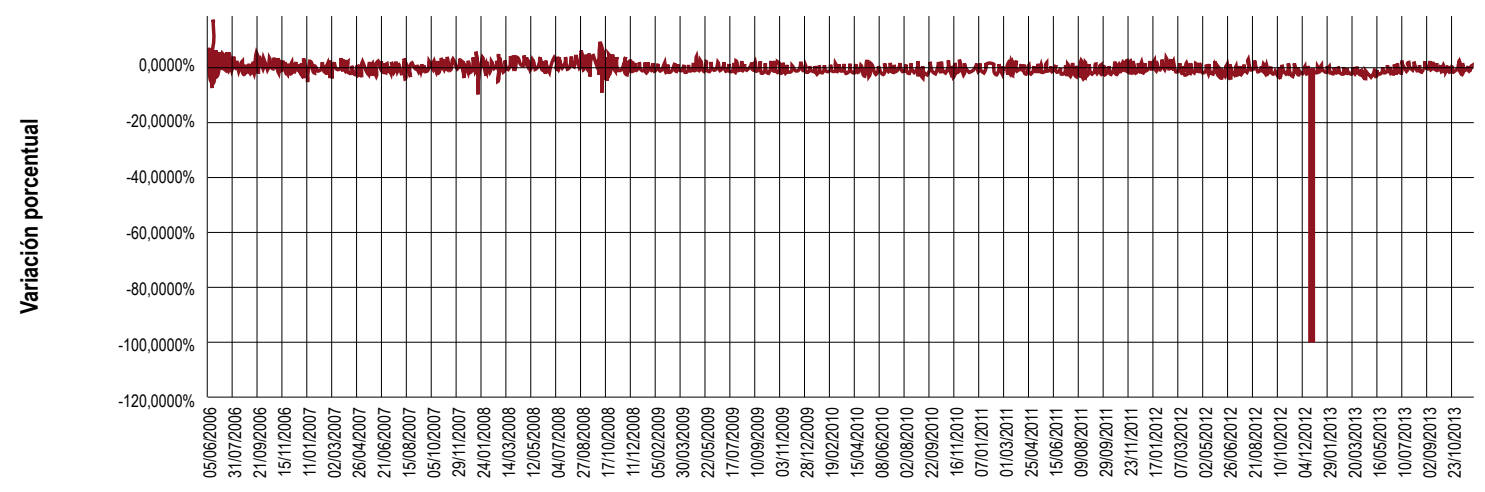

Fuente: tomado de la Bvc y Banco de la República años 2006 a octubre de 2013.

De las anteriores figuras, se concluye que el mercado accionario colombiano presentó una fuerte caída en el periodo comprendido de diciembre de 2012 a febrero de 2013, situación que se representó debido a la intervención y correspondiente liquidación de Interbolsa y el impacto que tuvo la misma en el mercado accionario.

\section{Impacto de la crisis financiera internacional del 2008 en el mercado de valores colombiano}

A pesar del impacto sistémico que representó la crisis financiera norteamericana para países desarrollados y emergentes ${ }^{7}$, Colombia no sufrió un fuerte impacto en sus mercados. Así, los principales efectos de la crisis financiera internacional se reflejaron en Colombia en los siguientes aspectos:

- Caída del índice accionario de la BVC en un $29 \%$ (AMv, 2009, p. 27).

$7 \mathrm{La}$ acumulación de reservas internacionales y los niveles más bajos de deuda externa permiten que algunos países en desarrollo se puedan proteger del rápido deterioro de los flujos de capital. Pero la contracción del crédito, su elevado costo y la volatilidad de las inversiones de cartera ya han resultado en la contracción de los flujos financieros. Los préstamos bancarios a mercados emergentes cayeron de un nivel máximo de US $\$ 4100001$ millones en 2007 a US $\$ 167000$ millones en 2008 y se prevé que bajen a US\$60000 millones en 2009 (Ocampo \& Griffith-Jones, 2009, p. 7).
- En materia fiscal, Colombia tuvo un déficit del Gobierno Central superior al 2\% (Ocampo, 2009, p. 26).

- Una depreciación del peso frente al dólar a partir del segundo semestre del 2008, pero no tan grave como en los otros países de la región (Ocampo, 2009, p. 25). Así, dicha situación se reflejó en las exportaciones y en la reducción del monto de las remesas (AMv, 2009, p. 28; Mesa, Restrepo y Aguirre , 2008, p. 48)

- El mercado de Tes no se vio afectado en Colombia (AMv, 2009, p. 29). Igualmente, dentro de la política monetaria el Banco de la República aumentó la compra de TES y disminuyó el monto de los encajes, todo con la finalidad de darle más liquidez a la economía (Mesa, Restrepo y Aguirre, 2008, p. 48).

- Los indicadores de cubrimiento, rentabilidad y solvencia del sistema financiero colombiano se mantuvieron positivos y estables. Esta situación permitió mitigar los efectos de la crisis y conservar la solidez del sector financiero colombiano (AMV, 2009, p. 27).

- Existió una disminución de la inversión en el exterior por parte de los intermediarios, razón por la cual dentro de sus portafolios solo representó un $0.9 \%$ (AMv, 2009, p. 29).

\section{Estructuración y evolución del MILA}

El mercado integrado latinoamericano MILA es un acuerdo firmado entre la Bolsa de Valores de 
Colombia, la Bolsa de Comercio de Santiago y la Bolsa de Valores Lima junto con los correspondientes depósitos de valores de cada uno de estos países (Deceval, Cavali y DCV) con la finalidad de facilitar la negociación de renta variable entre los citados Estados. Por otra parte, en el año 2014 la Bolsa Mexicana de Valores e Indeval ingresaron al MILA realizando su primera transacción en diciembre del citado año.

Así, el mila no es un proceso de unificación regulatorio entre los cuatro países encaminado a facilitar tanto la emisión como la negociabilidad de valores, ya que cada Estado mantiene su marco regulatorio y de supervisión. No obstante, el MILA tiene como finalidad buscar en el largo plazo un escenario, ya sea de unificación o armonización de los cuatro países en materia de mercado de valores.

De acuerdo con información del mismo MILA, para el 2017 contaba con 705 emisores, 37 intermediarios interconectados de los 4 Estados, más de 1000 valores transados y con una capitalización bursátil de más de US790 000 millones (MILA, 2017).

Un aspecto importante para tener en cuenta dentro de este proceso de integración es la expedición del Decreto 1756 de 2017 en lo referente a los fondos de inversión en el exterior (Ministerio de Hacienda y Crédito Público, 2017). A través de la citada regulación, se permite que operen en Colombia vehículos de inversión colectiva que estén autorizados en otros países con los cuales la Superintendencia Financiera de Colombia cuente con acuerdos o convenios de intercambio de información.

\section{Crisis de Interbolsa y su impacto en el mercado de valores de Colombia}

Interbolsa, además de que era la comisionista de bolsa de valores más grande de Colombia, buscó diversificarse a través de una estructura de holding. De esta manera, se creó un complejo conglomerado mixto (entidades financieras y del sector real) a partir de inversiones en mercados internacionales, entidades financieras (Interbolsa Panamá, Interbolsa Brasil, Interbolsa Securities, entre otras) y empresas del sector real (BMC, Grupo EMI, Odinsa, Coltejer, Fabricato, Easyfly) (Beethoven, 2017, p. 438).
Desde el año 2009 Interbolsa apalancó a un inversionista en aras de buscar una participación accionaria en Fabricato. De esta manera, el inversionista, con el fin de querer obtener el control accionario de la cita textilera, decidió obtener financiamiento de Interbolsa, a través de la materialización de operaciones repo (Corredor $\mathrm{Hi}$ guera, 2018).

Por medio de esta operación, Interbolsa financiaba al inversionista para la adquisición de acciones y este dejaba en garantía las mismas acciones de la textilera, lo cual llevó a que se convirtiera en el principal accionista de la empresa. Igualmente, Interbolsa replicó este tipo de operaciones con otros clientes, trayendo como consecuencia que la comisionista se quedará con 300000 millones de pesos de repos en acciones de Fabricato (Ochoa, González, Moreno, Bogotá y Rodríguez, 2012). Además de las acciones de Fabricato, esta práctica se replicó con acciones de InterBolsa, Coltejer, la Bolsa Mercantil de Colombia y Odinsa (Beethoven, 2017, p. 439) ${ }^{8}$.

Para el caso de Fabricato, el precio de la acción pasó de 26 a 90 pesos, teniendo un alto nivel de bursatilidad en la BVC. Sin embargo, la textilera nunca fue adquirida por inversionistas nacionales o extranjeros y ante las preocupaciones del mercado por el alto costo de la acción, se dejan de adquirir dichos valores en el mercado llevándolo a la baja. Dicha situación activó las garantías de los repos, llevando a Interbolsa a colocar recursos propios y de préstamos de instituciones financieras para cumplir, lo que empezó a generar problemas de liquidez de la comisionista (Corredor Higuera, 2018).

8 Así, en palabras de Beethoven: "En el manejo de los repos de estas compañías los conflictos de intereses y la manipulación de los precios fueron más que evidentes: las acciones de InterBolsa, Fabricato, Coltejer, BMC y Odinsa tenían características similares. Eran de baja bursatilidad y de compañías en las que InterBolsa Holding o algunos de sus principales accionistas tenían un interés particular. Con los repos podrían llegar a obtener el control de dichas compañías, y al influir en el precio de su cotización en Bolsa, generar utilidades por valorización muy considerables que daban una sensación de riqueza que les permitía seguir apalancándose”. 
Sumado a este escenario, se presentó un uso indebido de los recursos captados del público para apalancar las operaciones realizadas por la comisionista. De esta manera, la comisionista, a través de un entramado de empresas extranjeras y de contratos de corresponsalía, hizo uso indebido de los recursos que fueron captados en Colombia a través de tres fondos de inversión constituidos en Curazao (Rodríguez, 2014).

\section{Posibles puntos para tener en cuenta frente al mercado de valores colombiano}

\section{Modificación del concepto de valor}

A pesar de la existencia de una regulación frente al concepto de valor, en la práctica se han presentado una serie de problemas en relación con cierto tipo de productos que tienen la naturaleza de valor, pero no se les ha podido dar el tratamiento regulatorio y de supervisión, por no contar con el correspondiente decreto de reconocimiento.

Así, los derechos fiduciarios en algunos casos son reconocidos como valores cuando estos son producto de procesos de titularización. Igualmente, se comparte la posición de Varón y Abella al afirmar que algunos tipos de derechos fiduciarios pueden ser considerados como valores dentro del concepto de capitales de riesgo (Varón Palomino \& Abella Abondano, 2013, p. 62).

No obstante, en otros modelos negociales que se financian a través de mecanismos fiduciarios (como el caso de los Fidis ${ }^{9}$ ), se han generado

9 Dentro del concepto de FIDI, se puede establecer que "FIDI, es un acrónimo que significa 'figura internacional de derecho fiduciario inmobiliario', comercializados por FiDiGlobal, esta modalidad de inversión permite a los pequeños inversionistas obtener una participación en los proyectos inmobiliarios más importantes del país y del continente, sin necesidad de contar con un gran capital (...). Un Fidi es un parte alícuota de una propiedad inmobiliaria, es decir, que quien compra uno, se hace dueño de una fracción del inmueble, y su rentabilidad dependerá de la explotación del mismo y su valorización, lo verdaderos instrumentos financieros que responden a las características de los valores, pero, por no contar con el reconocimiento estatal, no se le ha dado dicho tratamiento. Sumado a tal situación, el público que invirtió en estos derechos fiduciarios no está cobijado por una serie de derechos propios de los inversionistas del mercado de valores, tales como suministro de información periódica, asesoría, valoración de clientes, mayor intervención por parte del supervisor, garantías dentro del proceso de emisión, entre otros ${ }^{10}$.

Otro ejemplo es lo relacionado con mecanismos de financiamiento a través de crowdfunding. Así, el crowdfunding de inversión y de financiamiento no ha tenido un desarrollo en Colombia debido a la ausencia de regulación sobre la materia, en especial, en lo relacionado con los procesos de captación no autorizada de recursos y porque los instrumentos emitidos por los promotores del proyecto no tenían la naturaleza jurídica de valores tanto en el artículo $2^{\circ}$ de la Ley 964 como por parte del Gobierno Nacional.

Solamente, con los proyectos de regulación en materia de crowdfunding expedidos por el Ministerio de Hacienda y Crédito Público se le estaría

que lo hace ideal también para los inversionistas extranjeros, ya que estos a través de sus derechos sobre el fideicomiso reciben una renta mensual por los usos del inmueble, y además les permite ahorrar muchos de los trámites, impuestos y registros que normalmente se originan en la transferencia de inmuebles" (Revista Dinero, 2015).

10 La Superintendencia Financiera de Colombia, a través de la Parte II, título II, Capítulo I de la Circular Externa 034 de 2018, procedió a dar instrucciones a sus vigiladas en lo relacionado con los negocios fiduciarios a través de los cuales se comercializan participaciones fiduciarias: "Son aquellos negocios en virtud de los cuales una persona natural o jurídica, mediante la transferencia de la propiedad a una sociedad fiduciaria, de uno o más bienes determinados, prevé la comercialización de participaciones fiduciarias en un fideicomiso, las cuales otorgan a los inversionistas el derecho a participar de los resultados económicos derivados del cumplimiento de una finalidad específica, sin que implique la propiedad del bien objeto el proyecto $y$, sin perjuicio, del ofrecimiento de beneficios adicionales". 
dando la denominación de valores: "Para los efectos de los previsto en el artículo $2^{\circ}$ de la Ley 964 de 2005 se entenderá que los instrumentos representativos de deuda o de capital, emitidos en las plataformas de financiamiento colaborativo tendrán la calidad de valores" (Ministerio de Hacienda y Crédito Público, 2016).

Bajo este panorama se plantea como solución que en Colombia se le dé el tratamiento jurídico de valor a los contratos de inversión, tal y como sucede en el caso norteamericano. Así, en la Sec 3 (10) de la Securities Exchange Act fo 1943 al definir el concepto de security señala: "(10) The term 'security' means (...) investment contract” (Senate and House of Representatives of the United State of America, 1934).

En cuanto al alcance de lo que se debe entender por contrato de inversión, la jurisprudencia norteamericana ha tenido un papel fundamental en la materia. Así, en el caso SEC $v$ W. J. Howey Co, se estableció que:

For purposes of the Securities Act, an investment contract (undefined by the Act) means a contract, transaction, or scheme whereby a person invests his money in a common enterprise and is led to expect profits solely from the efforts of the promoter or a third party, it being immaterial whether the shares in the enterprise are evidenced by formal certificates or by nominal interests in the physical assets employed in the enterprise (SEC v. Howey Co, 1946).

De la anterior definición, se puede concluir que se está frente a un contrato de inversión cuando existe: (i) inversión en dinero; (ii) empresa en común; (iii) expectativa de ganancia; y (iv) esfuerzo de otros (López Álvarez , 2008, p. 20; Gordon, 2011, p. 60).

Bajo esta figura, el supervisor financiero colombiano tendría la facultad de establecer en cada caso cuándo se estaría frente a un contrato de inversión, con el fin de darle el tratamiento de valor y de esta manera se estaría frente a un mecanismo de intervención ágil que protegería a los inversionistas y al mercado.

\section{Mitigación de conflictos de intereses al interior del regulador financiero}

Tal y como se comentó en una sección anterior de este documento, las funciones del MHCP de regulación financiera y emisor de deuda pública podrían generar cierto tipo de conflictos de intereses, es decir, problemas en materia de gobierno corporativo al interior del Ministerio.

Una posible solución es la de establecer al interior del MHCP criterios de mitigación de conflictos de intereses entre las dependencias de la entidad. Otra solución más radical sería que el presidente de la República delegara o desconcentrara la función de regulación financiera a una entidad independiente. No obstante, la Corte Constitucional en la Sentencia C-675 de 1998 determinó que de una interpretación de los artículos 115 y 335 de la Constitución Política la facultad de intervención del Gobierno no puede ser trasladada al Ministerio de Hacienda y Crédito Público ${ }^{11}$, ya que dicha competencia solo está en cabeza del Gobierno Nacional (Corte Constitucional, 1998).

Sin embargo, se comparte la posición de López Roca, según la cual ni el esquema constitucional de intervención del Estado en los mercados financieros, así como tampoco la sentencia de la Corte Constitucional prohíben que el Congreso autorice al presidente a delegar o desconcentrar su función

11 Así, la Corte Constitucional a través de la Sentencia C- 675 de 1998 determinó sobre el punto: "Si en virtud de la preceptiva del art. 335 la intervención del Gobierno en las referidas actividades corresponde privativamente al Gobierno, es decir, que debe ser ejercida en los términos del art. 115 de la Constitución por el Presidente de la República y el Ministro de Hacienda y Crédito Público, no encuentra la Corte justificado constitucionalmente que competencias de típica intervención, como las de los artículos 5, 6 y 7 de la Ley 35/93, que son del Gobierno, se trasladen al Ministerio de Hacienda y Crédito Público, así se emplee la fórmula equívoca y ambigua de que las facultades 'serán ejercidas por el Gobierno Nacional' por conducto de dicho Ministerio. En tales circunstancias las referencias que la norma acusada hace a los arts. 5, 6, y 7 de la Ley 35/93 serán declaradas inexequibles". 
de intervención en una comisión o unidad regulatoria de forma parcial o total. De esta manera, la citada comisión o unidad regulatoria ejercería su facultad dentro de los términos de la ley marco, tal y como lo haría el Gobierno Nacional si no hubiese delegado dicha función (López Roca, 2012, p. 70).

\section{Implementación del mila en sus diferentes etapas}

Uno de los mayores retos regulatorios en Colombia es el desarrollo de la segunda etapa del MiLA, la cual buscará criterios de armonización o unificación en materia de mercado de valores entre los países miembros. El escenario para materializar esta situación es la Alianza del Pacífico, en donde los cuatro Estados parte pueden profundizar los temas más relevantes en aras de encontrar una integración en el mercado de valores regional.

Ahora bien, dentro de los principales temas por desarrollar dentro del esquema de integración del MILA se destacan.

\section{Disparidad en los sistemas de compensación y liquidación}

En la etapa de cumplimiento de las operaciones sobre valores, existe una serie de disparidades entre los modelos regulatorios de los cuatro países en lo referente al sistema de anotación en cuenta en los depósitos de valores y los sistemas de compensación y liquidación.

En lo referente a los sistemas de compensación y liquidación, cada uno de los países cuenta con sistemas de compensación y liquidación por neteo, forma bruta o a través de las cámaras centrales de riesgo de contraparte (CCRC). El problema de fondo es que cada modelo institucional cuenta con un sistema de compensación y liquidación diferente, lo que a la postre tiene que ser solucionado en una futura integración a través de la implementación de un único sistema (bruto o neteo) y determinando cuáles operaciones deben ser realizadas a través de la CCRC.

De esta manera, se mitigarán problemas como el alcance del principio de finalidad de las operaciones (tiempo en el cual las operaciones son firmes) y otro tipo de riesgos legales y operativos.

\section{Armonización en la propiedad de los valores}

Relacionado con el punto anterior, se está ante la disyuntiva de los sistemas de propiedad de valores, es decir, si en los depósitos de valores la propiedad se encuentra en cuentas individuales o cuentas ómnibus. Así, en el sistema chileno la propiedad de los valores se materializa en cuentas ómnibus, situación que dista del caso colombiano y peruano (Baquero, 2013).

Dicha problemática se materializa en la práctica en relación con quien ostenta la propiedad de las acciones en los depósitos de valores y la individualización que se haga de dicha propiedad en las cuentas. Así, en las cuentas individuales la propiedad del valor corresponde al inversionista que se encuentre inscrito en el depósito a través de una anotación en cuenta, mientras que en las cuentas ómnibus la propiedad de los valores está en cabeza del intermediario de valores y este cuenta con unos sistemas de registro de propiedad a favor de cada inversionista.

Es interesante el ejemplo traído por Marín y Velandia al afirmar al respecto lo siguiente:

a título de ejemplo, piénsense en las limitaciones que existirían en cuanto a la propiedad de las acciones y el ejercicio de los derechos políticos que de ellas se derivan, cuando los titulares de las cuentas son quienes ostentan, a su vez, la titularidad de las acciones allí registradas, problema que se amplifica cuando se trata de inversionistas nacionales ejerciendo sus derechos políticos en empresas extranjeras y sin la regulación adecuada (Velandia y Marín, 2015, p. 16) .

Dentro de las posibles soluciones para la propiedad de los valores, las anotaciones en cuenta, los sistemas de compensación y liquidación y la firmeza de las operaciones, los cuatro Estados partes del MiLa podrían establecer unas normas de integración común desarrolladas al interior de la Alianza del Pacífico o adoptar dentro de sus ordenamientos jurídicos la convención de La Haya sobre ley aplicable a ciertos derechos sobre valores depositados en un intermediario (Convenio de La Haya, 2006) o el Convenio de Unidroit sobre las 
normas de derecho material aplicables a los valores intermediados (Unidroit, 2009).

\section{Reglas comunes para los procesos de emisión}

Se debe buscar que existan normas comunes para que cualquier emisor pueda presentar su solicitud de emisión en cualquier país y los demás Estados partes del mila lo reconozcan. Igualmente, se debe permitir que existan los mismos requisitos para la emisión de cualquier valor y que dichos instrumentos financieros tengan las mismas características en los cuatro países miembros.

\section{Modificación en la red de seguridad financiera frente a los intermediarios de valores e inversionistas}

Colombia cuenta con una red de seguridad financiera encaminada a prevenir, sanear y liquidar crisis financieras. Así, dicha red está conformada por el Banco de la República, el Fogafín, la Superintendencia Financiera de Colombia y el Ministerio de Hacienda y Crédito Público.

Ahora bien, dicha red está direccionada a solucionar los posibles problemas de liquidez de los establecimientos de crédito y para proteger a los depositantes. No obstante, en la actualidad no existen mecanismos efectivos dentro de la red para problemas de liquidez de los intermediarios de valores y para proteger los recursos entregados por los inversionistas.

En Colombia existe el Fogacol "Fondo de Garantías de las Sociedades Comisionistas de la Bolsa de Valores de Colombia”, que básicamente es un patrimonio autónomo, cuyos aportes son realizados por las comisionistas de bolsa de valores y administrado por la Fiduciaria Bancolombia ${ }^{12}$ (Fogacol, 2002).

$12 \mathrm{El}$ artículo $2^{\circ}$ del reglamento establece: "El Fondo tendrá por objeto responder a los clientes de las Sociedades Comisionistas de la Bolsa, incluidos los Fondos de inversión colectiva que administran, por el cumplimiento de las obligaciones de entrega o restitución de valores o de dinero que aquellas
No obstante, Fogacol desde su creación solo tenía como objeto darles liquidez a las comisionistas de Bolsa de Valores a través de la adquisición de valores. Con la liquidación de Interbolsa, se modificó la regulación del citado Fondo a través del Decreto 2255 de 2012 con el fin de que Fogacol le otorgue préstamos a las comisionistas, adquiera activos de comisionistas, invertir recursos en comisionistas con problemas de liquidez o solvencia, entre otros (Ministerio de Hacienda y Crédito Público, 2012).

Igualmente, Fogacol destina sus recursos para responder a los clientes no profesionales de las comisionistas de bolsa de valores frente al cumplimiento de las obligaciones de entrega o restitución de valores o de dinero que hayan contraído en desarrollo del contrato de comisión, de administración de valores y de administración de portafolios de terceros.

Ahora bien, si bien es cierto que Colombia adoptó la figura de un fondo de naturaleza privada con aportes privados ${ }^{13}$, es nuestra posición que tanto los canales de liquidez para los intermediarios de valores como la administración de los recursos de los fondos de garantías para inversionistas estén en cabeza del Fogafín.

Dicha afirmación se justifica en la experiencia que ha tenido el Fogafín desde el año de 1986 en materia de otorgamiento de liquidez a los establecimientos de crédito y en el pago de los seguros de depósitos en la crisis financiera de 1998 (Fogafín, 2009). De esta manera, se tendría una institución especializada, con experiencia en crisis financiera, que hace parte de la red de seguridad financiera, la cual podría realizar una mejor gestión de los recursos y establecer en tiempo de crisis cuáles son las mejores medidas tanto para los intermediarios de valores como para los inversionistas.

hayan contraído en desarrollo del contrato de comisión, la administración de valores y la administración de portafolios de terceros".

13 Dicho sistema ha sido adoptado por países como Canadá (Canadian Investor Protection Fund). 
Por otra parte, un tema complejo es lo pertinente a ampliar la cobertura del Banco de la República como prestamista de última instancia de los intermediarios de valores. En la actualidad, el Banco de la República solamente le puede otorgar liquidez a los establecimientos de crédito a través de operaciones de redescuento, cuando dichas entidades presentan problemas transitorios de liquidez mas no de solvencia ${ }^{14}$.

Para el caso del mercado de valores este sería un mecanismo excepcional, cuando los intermediarios de valores no puedan obtener liquidez en el mercado interbancario o a través de operaciones monetarias en el Banco de la República (omas permanentes o transitorias) ${ }^{15}$, ya que actualmente las comisionistas de bolsa, las fiduciarias y las AFP están autorizados a obtener liquidez a través de estos dos medios.

\section{Impacto de las nuevas tecnologías en el mercado de valores colombiano}

Actualmente, las nuevas tecnologías juegan un papel crucial en la prestación de productos y servicios financieros. Así, el uso de tecnología en los mercados financieros se ha denominado como Fintech (Arner, Janos \& Buckley, 2016). Tal dinámica se ha visto reflejada en los mercados de valores en los siguientes temas, los cuales necesitan contar con unas posibles respuestas regulatorias, según se muestra en la tabla 2.

Tabla 2. Impacto de las nuevas tecnologías en los mercados de valores

\section{Tecnología}

\section{High Frequency Trading}

Por negociación de alta frecuencia se entiende básicamente el uso de un algoritmo en la negociación de valores sin la intervención de humanos. Así, la computadora observa datos del mercado y demás información en alta frecuencia y, a través del algoritmo, realizar operaciones de trading en cuestiones de milisegundos (Chaboud, Chiquoine, Hjalmarsson, \& Vega, 2013).

\section{Posibles respuestas regulatorias}

Los grandes retos en materia de regulación y supervisión sobre el high frequency trading están encaminados a evitar que, a través de dicha tecnología, se manipulen los precios de los valores por medio de actividades fuera de la formación de los precios a través de la oferta y la demanda.

El reto en materia de regulación y supervisión está encaminado a entrar a determinar a quién le corresponde ejercer el deber de asesoría y frente a quién recaen las consecuencias jurídicas del incumplimiento de dicho deber, es decir, si dicha conducta está en cabeza de la institución financiera, del programador del algoritmo o del creador del algoritmo.

Dentro de los principales retos en los mercados de valores se encuentra el de adaptar dicha tecnología a las dinámicas de tales mercados, como contratos inteligentes frente a valores, modificaciones de las funciones de los depósitos de valores, ICO, entre otros (European Central Bank, 2016).

\section{Aplicación de tecnología blockchain}

El blockchain representa un avance tecnológico ya que, a través del mecanismo de base de datos distribuida, se permite registrar bloques de información y entrelazarlos, con el fin de facilitar su recuperación y poder verificar que dicha información no ha sido cambiada. Así, dicha tecnología tiene un potencial de aplicación en diversas áreas, destacándose las criptomonedas, la trazabilidad de procesos, los contratos inteligentes, los sistemas de pago, préstamos y demás actividades de los mercados bancarios y valores (Government Office for Science, 2016).

Fuente: elaboración propia.

14 Sobre el particular consultar el artículo 373 de la Constitución Política de 1991 y los artículos 12 y 52 de la Ley 31 de 1992.

15 Cuando se presentó la liquidación de Interbolsa, el día 7 de noviembre el Banco de la República abrió canales de liquidez a las comisionistas de bolsa, las fiduciarias y las AFP a través de omas transitorias.

\section{Repensar el proceso de supervisión y autorregulación en el mercado de valores colombiano}

A través del Decreto 1848 de 2016 se modificó la estructura interna del supervisor y se fortaleció el proceso de supervisión del mercado de valores a 
través de la creación de la delegatura adjunta para supervisión de emisores, administradores de activos e intermediarios de valores.

Se considera que esta fue una medida idónea y acorde a las necesidades del mercado local, ya que se fortalece el proceso de supervisión de los mercados de valores a través de delegaturas que se encargan de realizar un proceso de supervisión al mercado pensional, fiduciario, a emisores, intermediarios de valores y proveedores de infraestructura.

En cuanto al proceso de autorregulación, el escándalo de Interbolsa golpeó fuertemente la figura, razón por la cual muchos actores del sector abogan por cambios en su funcionamiento (Revista Dinero, 2017). Así, dentro de las principales críticas se destacan los elevados costos en que incurren los intermediarios por ser parte del proceso de autorregulación, la percepción de contar con dos supervisores, la ausencia de personas conocedoras del mercado dentro de la AMV, la obligatoriedad de estar dentro de un proceso de autorregulación, entre otros aspectos.

Por otra parte, si bien el proceso de autorregulación del mercado de valores cuenta con una intervención del Estado en su desarrollo, se considera que la expedición de la Circular Externa 004 de 2017 (Superintendencia Financiera de Colombia, 2017) desnaturaliza el proceso como tal. Tal afirmación se justifica en el hecho en que el autorregulador está obligado a suministrarle a la SFC informes sobre sus políticas de regulación, supervisión y sanción al igual que un informe sobre cómo está desarrollando dichas actividades. De esta manera, la AMV está recibiendo el trato de supervisión propio de una entidad vigilada, generando que pierda cierto grado de autonomía del que deben gozar los organismos de autorregulación.

\section{Conclusiones}

La Ley 964 de 2005 representó un cambio trascendental en el mercado de valores colombiano, ya que actualizó los procesos de intervención del Estado tanto a las dinámicas de los mercados internacionales y local como a los estándares internacionales de la materia.
En los trece años de vigencia de la citada Ley, se ha presentado una serie de desarrollos normativos al igual que nuevas realidades del mercado, representadas en procesos de integración, crisis, concentración del mercado e impacto de las nuevas tecnologías.

La regulación debe buscar que el mercado de valores colombiano se convierta en un mecanismo de financiación efectivo y de fácil acceso para las empresas y, de esta manera, establecer estrategias para evitar la alta concentración que existe hoy en día en el mercado, tanto en la negociación de TES como en los pocos emisores de acciones que existen en la actualidad.

Una de las estrategias para conseguir tal objetivo es la implementación de mecanismos de flexibilización regulatoria para la emisión por parte de pequeñas y medianas empresas. Igualmente, las nuevas tecnologías cumplen un papel fundamental para tal fin, tal y como ha ocurrido con plataformas de financiamiento colaborativo o con la implementación de tecnologías de bloques.

\section{Referencias}

AMv. (2009). Impacto de la crisis financiera internacional en el sistema financiero colombiano y en su regulación. Autorregulador del mercado de valores, 1-78. Obtenido de http://www.amvcolombia.org.co/attachments/data/ Impactodelacrisis.pdf

Ariza Marin, E. L. (2009). Autorregulación en el mercado de valores en Colombia: análisis de su aspecto disciplinario. Revista Maestria Derecho Económico, 5(5), 155-200.

Arner, D., Janos, N. \& Buckley, R. (2016). The Evolution of Fintech: A new post-crisis paradigm? University of Hong Kong Faculty of Law Research Paper, 62. Recuperado de https://www.law.georgetown. edu/academics/law-journals/gjil/recent/upload/Arner-Barberis-and-Buckley.PDF

Baquero, M. (2011). Regulador unificado y confianza en el mercado de valores. En: C. Blanco \& M. Baquero, Cinco años de la Ley 964 de 2005. ¿Se están cumpliendo sus objetivos? (pp. 61 a 128). Bogotá: Universidad Externado de Colombia.

Baquero, M. (2013). Legal Certainty and Financial Markets Integration: the MILA case. Law and Business Review of the Americas, 19, 487-502. Obtenido de 
https://scholar.smu.edu/cgi/viewcontent.cgi?article $=1149 \&$ context $=$ lbra

Beethoven, H. (2017). Globalización financiera: Banca, Regulación y crisis (p. 792). Bogotá, Colombia: Universidad Externado de Colombia.

Blanco, C. (2011). La ley 964 de 2005 y la protección de los inversionistas. En: C. Blanco, \& M. Baquero, Cinco años de la Ley 964 de 2005. ¿Se están cumpliendo sus objetivos? (pp. 229- 258). Bogotá: Universidad Externado de Colombia.

Chaboud, A., Chiquoine, B., Hjalmarsson, E. \& Vega, C. (2013). Rise of the Machines: Algorithmic Trading in the Foreign Exchange Market. Federal Reserve International Finance Discussion Paper $n .^{\circ}$ 980, 1-38. Recuperado de http://idei.fr/sites/default/files/medias/ doc/conf/euronext_ercbiais_anrdeclerck_0413/programme/vega_chaboud_chiquoine_hjalmarsson_paper_hft.pdf

Congreso de la República. (1979). Ley 32. Bogotá, Colombia.

Congreso de la República. (1993). Ley 35. Bogotá, Colombia.

Consejo Nacional de Política Económica y Social. (2005). Documento Conpes 3399 Programa de renovación de la administración pública: reforma de la institucionalidad para la regulación y la supervisión de los mercados financieros. Bogotá: Conpes.

Convenio de La Haya. (2006). Convenión de La Haya sobre ley aplicable a ciertos derechos sobre valores depositados en un intermediario. La Haya. Recuperado de https://www.hcch.net/es/instruments/conventions/ full-text/?cid=72

Corredor Higuera, J. (2018). Las implicaciones de los procesos de corrupción frente a las crisis financieras en Colombia: reflexiones en materia de regulación, supervisión, sanción y autorregulación. En: J, Henao \& C, Ruiz, Corrupción en Colombia: corrupción privada Corrupción en Colombia (pp. 244 a 277). Bogota: Universidad Externado de Colombia.

Corte Constitucional. (1995). C-397. Bogotá: Corte Constitucional.

Corte Constitucional. (1998). C-675. Bogotá: Corte Constitucional.

Corte Constitucional. (2006). C-860. Bogotá: Corte Constitucional.

Deutsche Bank. (2017). Robo-advice. A true innovation in asset management. EU Monitor Global financial markets, 1-16. Recuperado dehttps://www.dbresearch.com/ PROD/RPS_EN-PROD/PROD0000000000449125/
Robo-advice_-_a_true_innovation_in_asset_managemen.PDF

Estrada, D. y Gutiérrez, J. (2008). Supervisión y regulación del sistema financiero: modelos, implicaciones y alcances. Borradores de Economía-Banco de la República (490), 3-37.

European Central Bank. (2016). Distributed ledger technologies in securities post-trading. Revolution or evolution? Frankfurt: European Central Bank.

Fogacol. (2002). Reglamento del Fondo de garantías de las sociedades comisionistas de la Bolsa de Valores de Colombia. Fogacol. Bvc. Recuperado de https://www. bvc.com.co/pps/tibco/portalbvc/Home/Regulacion/ Fogacol?com.tibco.ps.pagesvc.action=updateRenderState\&rp.currentDocumentID=5d9e2b27_11de9ed172b_-2fa47f000001\&rp.revisionNumber $=1 \&$ rp. attachmentPropertyName $=$ Attachment\&com.tibco. ps.pagesvc.targetPa

Fogafín. (2009). Crisis financiera colombiana en los años noventa. Origen, resolución y lecciones institucionales. Bogotá: Universidad Externado de Colombia-Fogafín.

Forigua, J. (2011). Reflexiones en torno al concepto de valor. En C. Blanco y M. Baquero, Cinco años de la Ley 964 de 2005. ¿Se están cumpliendo sus objetivos? (pp. 379-392). Bogota: Universidad Externado de Colombia.

Gordon, J. (2011). Defining a Common Enterprise in Investment Contracts. Ohio State Law Journal, 72(1), 60-93.

Government Office for Science. UK (2016). Distributed Ledger Technology: beyond block chain. London: Government Office for Science.

Iosco. (2010). Objectives and Principles of Securities Regulation. Madrid: International Organizations of Securities Commissions.

Llewellyn, D. (2006). Estructura institucional de la regulación y supervisión financiera: Aspectos básicos. Washington: Banco Mundial.

López Alvarez, A. L. (2008). Introducción a la regulación de valores en los Estados Unidos. Revista e- mercatoria, 7(2), 1-85.

López Roca, L. F. (2011). El concepto de valor de la Ley 964 de 2005 frente a la noción de Mercado Público de Valores. En: C. Blanco y M. Baquero, Cinco años de la ley 964 de 2005. ¿Se están cumpliendo sus objetivos? (pp. 157-180). Bogotá: Universidad Externado de Colombia. 
Lopez Roca, L. F. (2012). El principio de igualdad en la actividad financiera. Bogotá: Universidad Externado de Colombia.

Mesa, R., Restrepo, D. y Aguirre, Y. (2008). Crisis externa y desaceleración de la economía colombiana en 20082009: coyuntura y perspectivas. Perfil de Coyuntura Económica (69), 31-67.

mila. (2014). Indicadores-mila. Recuperado en abril de 2015, de http://www.mercadomila.com/componentes/ imagenes/mila_news_no_28v2.pdf

MILA. (2017). MILA sigue como principal mercado de la región en términos de capitalización bursátil, con US790 mil millones. Recuperado de http://mercadomila.com/ home/files/comunicados/2017v2/201702_Noticias_ MILA_News_Febrero.pdf

Ministerio de Hacienda. Departamento Administrativo de la Función Pública. (2016). Decreto 1848. Bogotá, Colombia.

Ministerio de Hacienda y Crédito Público. (2017). Decreto 1756. Bogotá: Ministerio de Hacienda y Crédito Público.

Ministerio de Hacienda y Crédito Público. (1993). Decreto 653. Bogotá, Colombia: Diario Oficial, 40816.

Ministerio de Hacienda y Crédito Público. (2004). Exposición de Motivos del Proyecto de Ley del Mercado de Valores al Congreso de la República de Colombia. Bogotá: Ministerio de Hacienda y Crédito Público.

Ministerio de Hacienda y Crédito Público. (2012). Decreto 2255. Bogotá, Colombia.

Ministerio de Hacienda y Crédito Público. (2016). Proyecto de Decreto: por el cual se modifica el Decreto 2555 de 2010 para reglamentar la actividad de administración de plataformas electrónicas de financiación colaborativa. Bogotá: Ministerio de Hacienda y Crédito Público. Obtenido de http://www.minhacienda.gov. co/HomeMinhacienda/ShowProperty?nodeId=\% 2FOCS\%2FP_MHCP_WCC-094534\%2F\%2FidcPrimaryFile\&revision=latestreleased

Ocampo, J. A. (2009). Impactos de la crisis financiera mundial sobre América Latina. Revista Cepal, 97, 9-32.

Ocampo, J. \& Griffith-Jones, S. (2009). The Financial crisis and its impact on developing countries. Discussion Paper. New York: United Nations Development Programme. Obtenido de http://www.undp. org/content/dam/aplaws/publication/en/publications/poverty-reduction/poverty-website/the-financial-crisis-and-its-impact-on-developing-countries/ PG-2009-001-discussion-paper-financial-crisis-Griffith-Jones_Ocampo.pdf
Ochoa, P., González, J., Moreno, A., Bogotá, C. y Rodríguez, C. (2012). Descalabro Bursátil. Revista Dinero, págs. 159-214. Recuperado de http://premiosimonbolivar.com/inscripciones/anexos/descalabro_bursatil. pdf

Revista Dinero. (2015). El Modelo FiDi, una alternativa de inversión. Revista Dinero. Recuperado de http://www. dinero.com/especiales-comerciales/articulo/el-modelo-fidi-alternativa-inversion/180953

Revista Dinero. (2017). Las dudas frente al Autoregulador del Mercado de Valores (Amv). Revista Dinero. Recuperado de http://www.dinero.com/edicion-impresa/ pais/articulo/amv-regulacion-del-mercado-de-valores-en-duda/243447

Rodríguez, N. (2014). El contrato de corresponsalía y su papel en el caso de Interbolsa. Prolegómenos, XVII(34), 123-145.

Rodriguez Fernández, M. (2014). Concepto, alcance y estructura de la autorregulación en el mercado de valores en Colombia. Revista E-mercatoria, 13(2), 29-66.

Sala General de la Superintendencia de Valores. (1995). Resolución 400. Bogotá, Colombia.

Sarmiento, D. (2010). La Misión Kemmerer y el control estatal. Apuntes contables. Revista científica de contabilidad (12), 79-90.

SEC v. Howey Co, 328 US 293 (United State Supreme Court 27 de 5 de 1946). Obtenido de https://supreme.justia. com/cases/federal/us/328/293/case.html

Senate and House of Representatives of the United State of America. (1934). Securities Exchange Act of 1934. Washington, United State. Obtenido de http://legcounsel.house.gov/Comps/Securities\%20Exchange\%20 Act\%20Of\%201934.pdf

Superintedencia de Sociedades. (2012). Superintendencia de Sociedades. 73 años de historia. Bogotá, Colombia: Superintendencia de Sociedades. Obtenido de https:// www.supersociedades.gov.co/Servicio_Ciudadano/ informacion_interes/Documentos\%20compartidos/ revista-supersociedades-73anios.pdf

Superintedencia Financiera de Colombia. (2005). Derechos. Valor. Oferta Pública. Concepto 20056-946. Bogotá: Superintendencia Financiera de Colombia.

Superintendencia de Valores. (1995). Resolución 1200. Bogotá, Colombia.

Superintendencia Financiera de Colombia. (2017). Circular Externa 004. Bogotá, Colombia: Superintendencia Financiera de Colombia.

Superintendencia Financiera de Colombia-Amv. (2007). Memorando de entendimiento entre la Superintendencia 
Financiera de Colombia y la Corporación Autorregulador del Mercado de Valores. Bogotá, Colombia: Superintendencia Financiera de Colombia-Amv.

Unidroit. (2009). Convenio de Unidroit sobre las normas de derecho material aplicables a los valores intermediados. Ginebra: Unidroit.

Varón Palomino, J. C. y Abella Abondano, G. (2013). Derechos fiduciarios y mercado de valores: reflexiones frente a la normatividad colombiana. Bogotá: Universidad de los Andes.

Velandia, L. y Marín, S. (2015). El sistema de compensación y liquidación en el MILA: un nuevo entendimiento regional en búsqueda de una mejor competitividad a nivel mundial. Autorregulador del Mercado de Valores, 1-25. Obtenido de http://www.amvcolombia.org.co/attachments/data/20151207142611.pdf 
